\title{
熔融 $\mathrm{CaO}-\mathrm{SiO}_{2}-\mathrm{Al}_{2} \mathrm{O}_{3}$ 鑛滓中の硫黃の擴散*
}

Tunezô Saitô and Yasuji Kawai : Diffusion of Sulphur in Molten CaO-SiO $\mathrm{Al}_{2} \mathrm{O}_{3}$ Slags. As the first step in the study on the kinetics of desulphurization of iron by slag, the rate of diffusion of sulphur in molten $\mathrm{CaO}-\mathrm{SiO}_{2}-\mathrm{Al}_{2} \mathrm{O}_{3}$ slag was determined by the use of radioactive sulphur $\mathrm{S}^{35}$. Iron sulphide powder made from barium sulphide containing $\mathrm{S}^{35}$ was mixed with slag powder and after melting, it was poured into a graphite tube to form a radioactive sample. Then, it was coupled with a graphite crucible containing a non-radioactive sample the composition of which was nearly the same as the former. This couple was heated in a high frequency induction furnace in nitrogen atmosphere for a definite time. After cooling $i$ in the furnace, small pieces were cut off successively from the top to the bottom and the radioactive intensities of polished surfaces of the remainder were measured by a Geiger-Müller counter. From these measurements, the diffusion coefficient of sulphur in molten basic slag was determined as follows : $D=1.4 e^{-\frac{49000}{R T}}$ The value of diffusion coefficient in acid slag at $1440^{\circ}$ was nearly the same as in basic slag, but values at higher temperatures could not be determined owing to the gas evolution by the reaction, $\mathrm{SiO}_{2}+2 \mathrm{C} \rightarrow \mathrm{Si}+2 \mathrm{CO}$. As shown from the results, the rate of diffusion of sulphur in molten slag is so slow that it seems to be the rate controlling factor governing the desulphurization of iron by slag.

(Received April 27, 1953)

\section{I. 緒}

熔鐵，㗪舒の脱硫に關する研究は數多いが，平衡論的立 場よりの研究が大部分で, 反㗹速度論的研究は少い. 最近

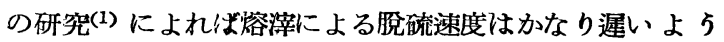

** 東北大學選鑛製鍊研究所

* 1952 年 11 月本會福岡大會に發表 ; 選鑛製鍊研究所 報告, 第 160 號

(1) G. Hatch, J.Chipman, Tr. AIME., 185 (1949), 274.
である・

熔㳯による脫硫は：(i) 熔鐵中の硫黃の搷散，(ii）跧鐵 一熔㳯界面に怙ける硫黄の移動, (iii) 熔㵏中の硫黄の撒散 ,に解析して考えることが出來る. 㥈鐵中の硫带の据散恒數 は Holbrook など(2)によると $10^{-3} \mathrm{~cm}^{2} / \mathrm{sec}$ 程度であり， 熔滓中の搌散恒數は Derge など(3)によると $10^{-5} \mathrm{~cm}^{2} / \mathrm{sec}$

(2) W. F. Holbrook, C. C. Furnas, T. L. Joseph, Ind. Eng. Chem., 24 (1932), 993.

(3) G. Derge, W. O. Philbrook, K.M. Goldman, Tr. AIME., 188 (1950), 1111. 
以下と報告されており，熔㴖中の擴散は熔鐵中の擴散に比 べかなり遲いよらである，從つて熔滓中の擴散が脫硫速度 を夌配する重要な因子と考えられる．このよらに擴散の遲 いもの小撗散恒數の決定には擴散時間を非常に長時間にす るか，むるいは境界面附近の濃度分布を特別の方法で精測 しなければならない. しかるに Dergeなどは化學分析によ る通常法を周いたから㹉散恒數の大體の值は制明したが, その溫度, 組成による變化などは測定出來なかつた.よつて 著者等は脫硫反㗹速度の研究の第一步として, 熔㳯中の硫 黄の撗散恒數の正確なる測定を試みた。最初に豫備實驗と して Dergeなどと同樣な方法で化學分析によつて擴散試 料の硫黄の濃度分布を調べたところ, 摭散恒數は 10-5 $\mathrm{cm}^{2} / \mathrm{sec}$ 程度であることが確められた. そこで放射性硫黃 S 35 を使周し擴散試料の境界面附近の濃度分布を精確に测 定する方沠により蛪散恒數を決定した.

\section{II. 試 料 調 整}

\section{1. 放射性硫黄 $\mathrm{S}^{35}$}

使周した放射性硫黄 $\mathrm{S}^{35}$ は米國製のもの $3 \mathrm{mC}$ で，最初 $1 \mathrm{mC}$ 次に $2 \mathrm{mC}$ の 2 回に入手したもので, 共に $\mathrm{BaS}$ の $\mathrm{Ba}(\mathrm{OH})_{2} 0.203 \mathrm{~N}$ の溶液であつた.濃度は約 $4 \mathrm{mC} / \mathrm{mL}$ で おつたので, $\left(\mathrm{NH}_{4}\right) \cdot \mathrm{S}$ 溶浚を carrier として添加した. $\mathrm{S}^{53}$ は $\beta$ 線 (最大エネルギー $0.17 \mathrm{MeV}$ ) のみを放射して原子 崩壤をし Cl35 になる. その牛減期は87.1 日とされている

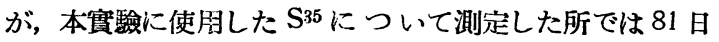
で幾分短くでた。

\section{2. 硫化鐵の製造}

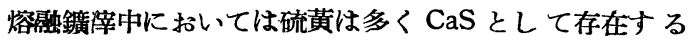

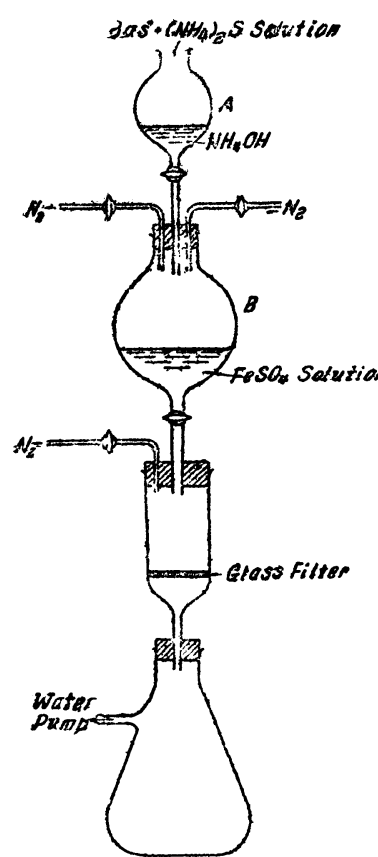

Fig, 1 Apparatus for Preparing FeS*.
と考えられている.よつ て入手した BaS* (*印 を附して放射性硫黄を含 有することを示す)より CaS*を製造し，これを 鑛䐠に添加与るのが穻當 と洘えられたがその操作 が面倒で，かつ損失も大 きいと豫想されたので FeS* を製造することに した. BaS*より FeS* 製造つ操作は次の如くで ある。

Fig.1 の B のフラス コに $\mathrm{FeSO}_{4}$ 溶液を入れ て置きこれに $\mathrm{A} の>$ ラスコより $\mathrm{NH}_{4} \mathrm{OH}$ を 滴下させて $\mathrm{Fe}(\mathrm{OH})_{2}$ 沈 澱を造る.引續いて BaS*特よび carrier で ある $\left(\mathrm{NH}_{4}\right)_{2} \mathrm{~S}$ の混合溶
液を同じくAのフラスコより滴下させる. この際 $\mathrm{BaS}^{*}$ が 完全に $\mathrm{FeS} *$ になるよらに $\mathrm{FeSO}_{4}$ 溶浓がBaS*+( $\left.\mathrm{NH}_{4}\right)_{2} \mathrm{~S}$ 混合溶液に對して過剩になるようにした. Bのフラスコ をよく振晸して

$$
\begin{array}{r}
\mathrm{BaS}^{*}+\mathrm{Fe}(\mathrm{OH})_{2} \rightarrow \mathrm{FeS} *+\mathrm{Ba}(\mathrm{OH})_{2} \\
\left(\mathrm{NH}_{4}\right)_{2} \mathrm{~S}+\mathrm{Fe}(\mathrm{OH})_{2} \rightarrow \mathrm{FeS}+2 \mathrm{NH}_{4} \mathrm{OH}
\end{array}
$$

反應を充分進ませた後, 溶液, 沈澱を一緒にフラスコの下 部のコックよりグラスフィルターに滴下させ水流ポンプで

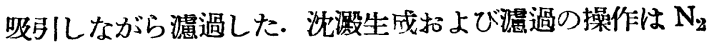
氣流中で行い沈澱の酸化を出杰るだけ防いだ. 生成した沈 澱 $\left(\mathrm{FeSO}_{4}\right.$ 過剩のため $\mathrm{Fe}(\mathrm{OH})_{2}, \quad \mathrm{Fe}(\mathrm{OH})_{3}$ をも含む) を寊茎中で約 $50^{\circ}$ に加熱乾燥した後. 磁製乳鉢で粉倅しガ ラス瓶に入れデシヶーター中に保存した. BaS* の入手時 期が 2 度に分れたので，最初は $1 \mathrm{mC}$ 次に $2 \mathrm{mC}$ の BaS* 溶液について以上の操作を行つた. $\mathrm{FeS}^{*}$ 粉末の製造量は 始めつ $1 \mathrm{mC}$ を使用した場合約 $4 \mathrm{~g}$, 後の $2 \mathrm{mC}$ を使用し た場合約 $3.2 \mathrm{~g}$ で共に約 $28 \% \mathrm{~S}$ であつた.

\section{3. 錪滨試料}

鑛㳯原料には石灰 ( $\mathrm{CaO} 99 \%)$ ，石英 $\left(\mathrm{SiO}_{2} 99.5 \%\right)$ ， アルミナ $\left(\mathrm{Al}_{2} \mathrm{O}_{3} 98.5 \%\right)$ の粉末を使㸝した.これらを所

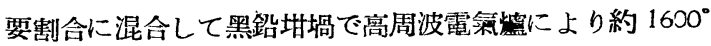

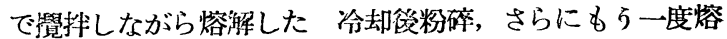
解して充分組成を均一にしたもの小牛分を粉末にし，牛分 を小塊にした. その組成は Table 1 に示す如くで，監基 性のもの 1 種類, 酸性のもの 2 種類であつた. 粉末の方には Table 1 Composition of Slags.

\begin{tabular}{l|r|r|r|r}
\hline & $\mathrm{CaO}(\%)$ & $\mathrm{SiO}_{2}(\%)$ & $\mathrm{Al}_{2} \mathrm{O}_{3}(\%)$ & $\mathrm{CaO} / \mathrm{SiO}_{2}$ \\
\hline Basic slag & 50.3 & 39.3 & 10.4 & 1.28 \\
Acid slag & 37.5 & 53.9 & 8.6 & 0.69 \\
" & 42.5 & 47.9 & 9.6 & 0.89 \\
\hline
\end{tabular}

FeS* 拈よび CaS (約 $23 \% \mathrm{~S}$ ) の粉末を混合して (FeS* のみでは S 量が不足なので $\mathrm{CaS}$ 女添加した約） $1.5 \% \mathrm{~S}$ になるよらにし,これを黑鉛 坩堝 (內巠約 $30 \mathrm{~mm}$, 深さ約 $90 \mathrm{mrn}$ ) に入れ密閉高周波電氣煇（Fig. 3) で熔解, 時々 㘫堝を迴轉させて攪拌效果を與え試料の均一化を促進させ

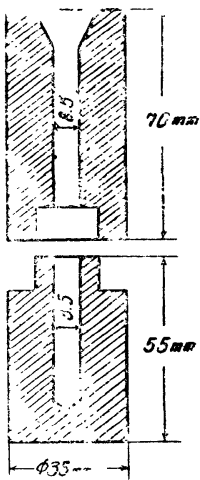

Fig. 2 Graphite Crucible for Diffusion Run. た後, 爐冷し, 坩堝から取出し $\mathrm{S}$ * 分布が均一であることを確めた啳， 擴散實驗の $\mathrm{S} *$ 含有鑛㳯試料に供し た. な括この熔解の際鑛滓中の鐵分 は小粒となつて分離した。

\section{III. 擴散實驗方法}

售散實驗には Fig. 2 に示寸如き 黑鉛容器を使用した。 まず圖の下部 の黑鉛坩堝を高周波電氣 爐で 加 熱 し，S*を含有しない鎨漳の小塊を氣 泡が出來ない上らに徐々に熔かし边 み冷却後上端を平滑に研磨 して 打

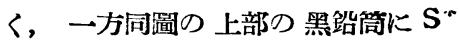


含有鑛㳯を 鑄込む。しかる 後兩者を 接着せしめ對となし Fig.3 の高周波電氣爐で所定溫度で所定時間（毁基性鑛 㳯の場合 5 時間, 酸性鑛㳯では短時間) 擴散を行わせた。

圖示の如く試料の溫度の抣一性をよくするために黑鉛坩堝 を二重にし黑鉛の蓋をかぶせた. そして S*が大氣中に蒸 發すると有害であるから爐をアスベストランバーで密閉し

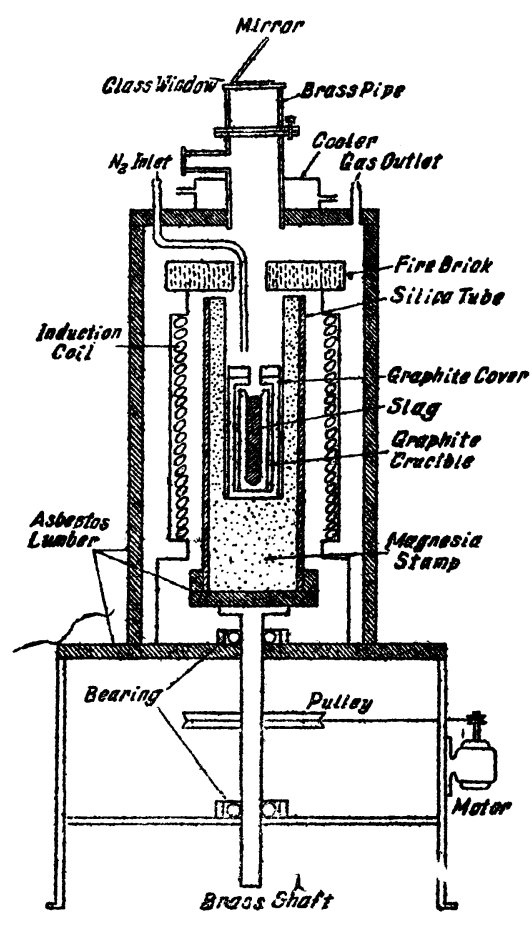

Fig. 3 Induction Furnace for Diffusion Run.
$\mathrm{N}_{2}$ 氣流中で

實驗を行つ

た. 測溫は豫

め $\mathrm{Pt}-\mathrm{Pt} \cdot \mathrm{Rh}$

熱電對で補正

した光高溫計

によつた. 所

要の贋散を行

わせたならば

爐冷し, 冷却

試料を黑鉛坩

堝に入れたま

$\checkmark$ 上端より小

量づつ順次切

り捨て研碄器

に取りつけて

ドラフト內で

研㰁し，研磨 面の放射性の 强さを Geiger-Müller 計 數管で測定し た. Geiger-

Müller 計數管は神戶工業 株式會藏製の 100 進法のもので 雲母空の厚さ $1.58 \mathrm{mg} / \mathrm{cm}^{2}$ であつた. 測定の際の幾何學 的條件を一定にするため鑛㳯試料面に俓 $7 \mathrm{~mm}$ の孔のある 真鍮板を接觸させ，その孔の位置が Geiger-Müller 管の 雲母器に對し常に同じ位置にくるよらにし，孔を通つてく る放射性の强さを測定した. 摭散界面附近の放射性の强さ の變化は重要なので, 微量づつ研磨して研磨量をマイクロ メーターで $1 / 100 \mathrm{~mm}$ まで䜋みとつて放射性の强さを測定 した. かくして試料の各斷面の放射性の强さを測定するこ とにより次に述べる方法で擴散恒數を求めた.

\section{IV. 摭散垣數の算出}

硫黄の擴散恒數が濃度に無關係とすると, $t$ 時間擴散後 の濃度分布は次式で表わされる.

$$
C_{x}=C_{0}\left(1-\frac{2}{\sqrt{\pi}} \int_{0}^{\frac{x}{2 \sqrt{D t}}} e^{-y 2} d y\right)
$$

こャに $C_{x}$ は界面より距離 $x$ に拈ける濃度, $C_{0}$ は最初の 濃度差の $1 / 2 ， D$ は擴散恒數である.

本實驗においては擴散後の試料を順次切斷研磨していつ て各斷面の放射性の强さを測定したのであるから，表面に
おける S*よりの $\beta$ 線以外に內部より逶過してきた $\beta$ 線 をも測定していることになる， $\beta$ 線は物臀によつて吸收さ れ，吸收物貿の厚さ $x$ と，透過してくる放射性の强さ $I$ の間には次の關係がある.

$$
I=I_{0} e^{-\mu x}
$$

こトに $I_{0}$ は吸收物質のない場合の放射性の强さ， $\mu$ は 吸收係數で S* の場合 $0.2 \sim 0.3 \mathrm{~cm}^{2} / \mathrm{mg}$ 程度である. 從つ て今界面より $a$ の距離まで研槩し去つて斷面の放射性の 强さを測つたとすると，測定している放射性の强さ $I_{a}$ は 次式の如く表わされる.

$$
I_{a}=k \int_{a}^{\infty} C_{x} e^{-\mu(x-a)} d x \text { 但し } x \geq a .
$$

こっに $k$ は測定つ幾何學的條件などに關係する常數であ る.上式に (1) 式を代入し計算すると結局次式が得られる.

$$
\begin{aligned}
& \Gamma_{a}=\frac{k C_{0}}{\mu}\left(1-\frac{2}{\sqrt{\pi}} \int_{0}^{\overline{2 \sqrt{D t}}} e^{-y^{2}} d y\right)- \\
& \frac{k C_{0}}{\mu} e^{\mu(a+\mu D t)}\left(1-\frac{2}{\sqrt{\pi}} \int_{0}^{-\frac{a}{\sqrt{t D}}+\mu \sqrt{D t}} e^{-y^{2}} d y .\right.
\end{aligned}
$$

$\mu=0.2 \sim 0.3 \mathrm{~cm}^{2} / \mathrm{mg}$ とし種々の $\sqrt{D t}$ およ゙ $a$ に對 して.上式の右邊の第 1 項, 策 2 項を計算してみると, 第 2 項は第 1 項に比べ無視しても差支えない程度に小さいこと がわかる.ナなわち本實驗の精度附で

$$
I_{a} \doteqdot \frac{k C_{\mathrm{n}}}{\mu}\left(1-\frac{2}{\sqrt{\pi}} \int^{\frac{a}{2 \sqrt{ } D \imath}} e^{-y^{2}} \cdot d_{y}\right)=\frac{k}{\mu} C a
$$

たドし、 $\sqrt{D t}$ の小さいほど， $a$ の大きいほど (4) 式の右 邊第 2 項を無視することによる誤差は大きい。

(5) 式より明らかな如く各斷面の放射性の强さを測定す ることにより試料內の S* 濃度分布が求められ，從つて常 用の方法により擴散恒數が決定できる．放射性の强さII が表面濃变 $C_{a}$ に比例すると見なして差支えないことは鑛 漳による放射線の吸收が著しいことよりも像想される.す なわち $\mu=0.2 \sim 0.3 \mathrm{~cm}^{2} / \mathrm{mg}$ といら值は鑛漳の比重を $3 \mathrm{~g} / \mathrm{cm}^{3}$ とすると, $600 \sim 900 \mathrm{~cm}^{-1}$ になり，鐄㴖の厚さの 埇加に上る透過放射線の强さの減少は著しい，たとえば $0.01 \mathrm{~cm}$ の厚さだと放射性の强さは吸收のない場合の 1/400～1/8000 程度になる. 從つて表面の極く薄い層の $\mathrm{S} *$ のみが計數管に檢知されるのである. その蒖い、層內でS*濃 度が一定と見做せば值ちに (5) 式が得られる

\section{V. 駘 結}

\section{1. 䁂基性鐄滓}

鑛㳯組成は Table 1 に示した如きもので, S* 含有鑛 滓はこの組成の鑛滓粉末に $\mathrm{FeS} *$ 括よび $\mathrm{CaS}$ を配合した もので配合㓶合， $\mathrm{S}$ 濃度，擴散實驗條件などを一括して Table 2 に示した.

撗散を行わせた後の試料內の S* 濃度分布を Fig. 4 に 示した. Derge 等の實驗では茎實驗（所定擴散溫度と常 溫間の加熱，冷却の過程に颃ける擴散の程度を調べた實 
Table 2 Data on Diffusion Runs (Basic Slag, $\mathrm{CaO} / \mathrm{SiO}_{2}=1.28$ )

\begin{tabular}{|c|c|c|c|c|c|}
\hline $\begin{array}{l}\text { Experi- } \\
\text { ment } \\
\text { No. }\end{array}$ & $\begin{array}{l}\text { Mixing Ratio } \\
\text { active Slags }\end{array}$ & for & Radio- & $\left|\begin{array}{l}\mathrm{S}(\%) \\
\text { A naly- } \\
\text { sed }\end{array}\right|$ & $\begin{array}{l}\text { Diffusion } \\
\text { Run }\end{array}$ \\
\hline No. 13 & $\begin{array}{l}\text { Slag } 9.2 \mathrm{~g}, \\
\text { CaS } 0.6 \mathrm{~g}\end{array}$ & FeS* & $0.2 \mathrm{~g}$ & 1.78 & $\begin{array}{r}1515 \pm 8^{\circ} \\
5 \mathrm{hrs}\end{array}$ \\
\hline No. 14 & " & " & " & 1.8) & $\begin{array}{c}1580 \pm 10^{\circ} \\
5 \mathrm{hrs}\end{array}$ \\
\hline No. 15 & " & " & "I & 1.75 & $\begin{array}{l}1500^{\circ}, 5 \mathrm{~min} \\
\text { (blank run) }\end{array}$ \\
\hline No. 16 & $0.3 \mathrm{~g}$ & & $05 \mathrm{~g}$ & 1.62 & $\begin{array}{c}1445 \pm 10^{\circ} \\
5 \mathrm{hrs}\end{array}$ \\
\hline No. 17 & " & " & " & 1.61 & $\begin{array}{r}158 \pm 10^{\circ}, \\
5 \text { hrs }\end{array}$ \\
\hline
\end{tabular}

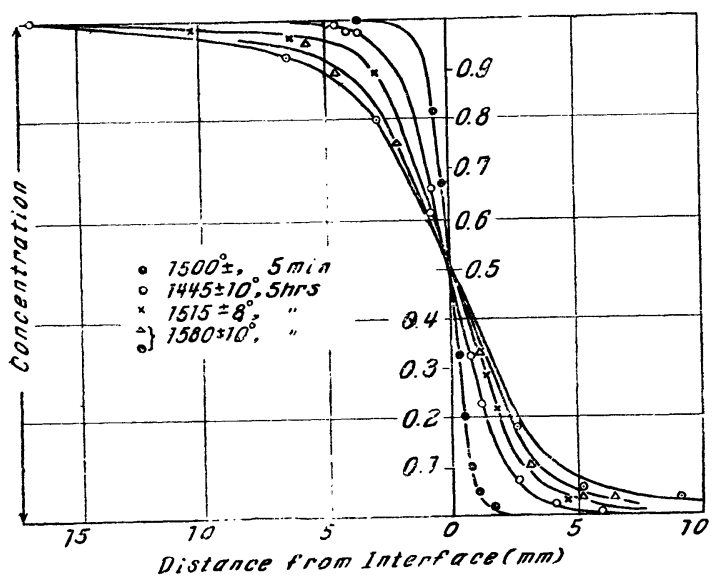

Fig. 4 Distribution of $\mathrm{S}^{*}$ after Diffusion in Basic Slag $\left.(\mathrm{Ca}) / \mathrm{SiO}_{2}=1.28\right)$.

驗）と拱散實驗の差が㦈とんど檢知できなかつたが，放射 性硫黄を使用した著者等の實驗では圖より明らかな如く空 實驗との差ばかりでなく，掘散溫度の相違による差も明瞭 に認められた、熔融鐄漟中の硫黄の擴散は非常に遲いので 茎實驗を各温湾について行ら必要はないと考えられるの で， $1500^{\circ} ， 5$ 分つ賽驗を室實驗として各實驗溫度の値より 差引きして撗散恒數を求めた、その結果を Table 3 に示 す. $100^{\circ}$ の溫度上年で $D$ の值はほら゙ 2 倍になる. 擴散恒 數と温菨の間には次の關係がある.

Table 3 Diffusion Coefficients of Sulphur in Basic Slag.

\begin{tabular}{r|c|c|c}
\hline Temperature $\left({ }^{\circ} \mathrm{C}\right)$ & 1445 & 1515 & 1580 \\
\hline $\begin{array}{r}\text { Diffusion coefficient } \\
\left(\mathrm{cm}^{2} / \mathrm{sec}\right)\end{array}$ & $0.89 \times 10^{-0}$ & $1.5 \times 10^{-0}+2.6 \times 10^{-6}$ \\
\hline
\end{tabular}

$$
D=A e^{-\frac{Q}{R T}} \text {. }
$$

こトに ひ は活性化ェネルギー，A は常數である．本實 驗より求めた $D$ の對數を絶體溫度の逆數に plotしてみる と，湘定値が 3 點つみで不足であるがほ心゙一直線上にある と見てよい(Fig.5). これより $A, Q$ の值を概算すると次 の如くである.

$$
D=1.4 \times e^{-\frac{49000}{R T}}
$$

\section{2. 酸性籍蚞}

姶めに Table 1 の $\mathrm{CaO} / \mathrm{SiO}_{2}=0.69$ とい5かな り酸性の
鑛漳について實驗を行つたが， $\mathrm{S}$ * 濃度分布は不規則異常

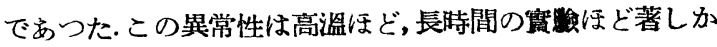

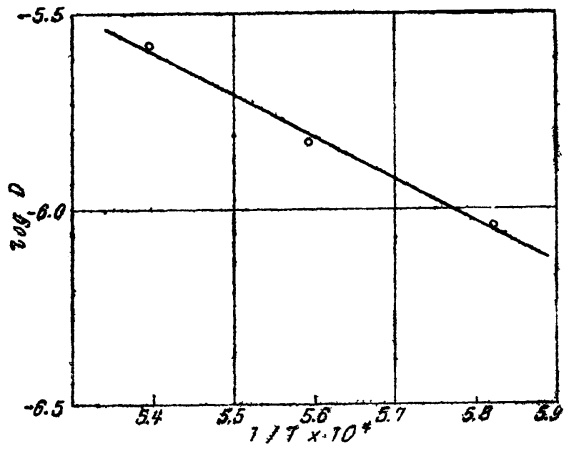

Fig. 5 Relation between $\log D$ and $1 / T$. つた. $\mathrm{SiO}_{2}$ 含有量の多い場合は $\mathrm{SiO}_{2}$ が坩堝の C と作閏 L

$$
\mathrm{SiO}_{2}+2 \mathrm{C} \rightarrow \mathrm{Si}+\mathrm{CO}
$$

の反應によつて CO ガスが發生し，熔蛬鑛㳯が覧亂される 結果 $\mathrm{S}^{*}$ 濃度分布が㟟常になると考えられる. よつて酸性 度の低い $\mathrm{CaO} / \mathrm{SiC}_{2}=0.89$ という鑛㳯を使用し，低溫度で しかも撗散時間を短かくして實驗を行つた，FeS*,CaSの 配合割合，S 濃隻，實驗條件を Table 4 に，拱散を行わせ

Table 4 Data on Diffusion Runs (Acid Slag, $\mathrm{CaO} / \mathrm{SiO}_{2}=0.89$ ).

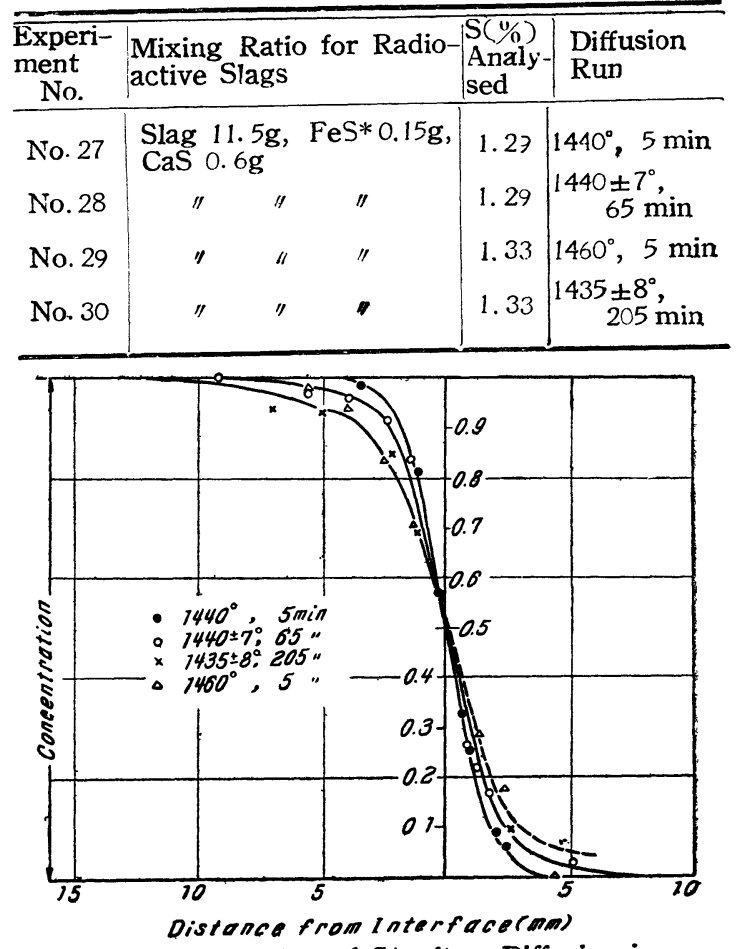

Fig. 6 Distribution of S* after Diffusion in Acid Slag $\left(\mathrm{CaO} / \mathrm{SiO}_{2}=0,89\right)$.

た試料內の S* 濃度分布を Fig. 6 に示した. 摭散時間 む 短かく精確な結果は求め難いが, 擴散恒數を概算してみる と $1440^{\circ}$ で $0.8 \times 10^{-6} \mathrm{~cm}^{2} / \mathrm{sec}$ 程度であつた. 高温にする 
とこの組成の䥊㳯でも $\mathrm{S} *$ 濃度分布は異常になり，從つて 掘散恒數の溫度變化を求めることは出來放かつた. しかし

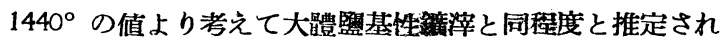
る.

\section{VI. 總括}

放射性硫黄 S35 を使用して熔融鑛漳中に扣ける硫黄の摒 散速度を測定した。その結果からみると硫黄つ逪散は塔鐵

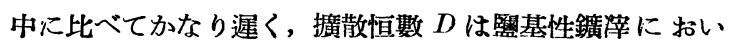
ては $0.89 \times 10^{-6}\left(1445^{\circ}\right), 1.5 \times 10^{-6}\left(1515^{\circ}\right), 2.6 \times 10^{-6}$ $\left.1583^{\circ}\right) \mathrm{cm}^{2} / \mathrm{sec}$ で溫旁による變化は次式で表わされた.

$$
D=1.4 \times e^{-\frac{49000}{R T}}
$$

すなわち $100^{\circ}$ の溫度上昇で $D$ の值はほ 2 倍になる. 酸 性鑛䐠の擴散恒數は約 $0.8 \times 10^{-6} \mathrm{~cm}^{2} / \mathrm{sec}\left(1440^{\circ}\right)$ であつ

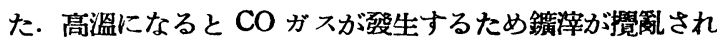
た濃度分布が不規則異常になり愅散恒數の溫度による變化 を湘定することが出來なかつた．これらの值は熔鐵中の硫 黃の擴散恒數が $10^{-3} \mathrm{~cm}^{2} / \mathrm{sec}$ 程度であるのに比べ著しく 小さい，從つて熔㳯中の硫黃の搌散が脫硫复雇の速度を支

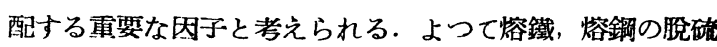
をよくするには熔鐵, 熔鋼と熔㴖の接觸面積を大きくする (たとえば覺䢁する)上う操業することが車要である.

終りに FeS* 製造に關し有湓な御助言を與えられた當研 究所岡教授ならびに實驗に助力された島貫良一，伊東值 哉, 佐藤弘つ諸君に厚く感謝する. 